\title{
Article \\ The Effect of a Peptide Substrate Containing an Unnatural Branched Amino Acid on Chymotrypsin Activity
}

\author{
Yuuki Yamawaki, Tomoki Yufu and Tamaki Kato * \\ Graduate School of Life Science and Systems Engineering, Kyushu Institute of Technology, 2-4 Hibikino, \\ Wakamatsu-ku, Kitakyushu 808-0196, Fukuoka, Japan; yamawaki.yuuki889@mail.kyutech.jp (Y.Y.); \\ tomoki.yufu0620@gmail.com (T.Y.) \\ * Correspondence: tmkato@life.kyutech.ac.jp
}

check for updates

Citation: Yamawaki, Y.; Yufu, T.; Kato, T. The Effect of a Peptide Substrate Containing an Unnatural Branched Amino Acid on Chymotrypsin Activity. Processes 2021, 9, 242. https://doi.org/ $10.3390 /$ pr9020242

Academic Editor: Kenji Usui Received: 28 December 2020 Accepted: 25 January 2021 Published: 28 January 2021

Publisher's Note: MDPI stays neutral with regard to jurisdictional claims in published maps and institutional affiliations.

Copyright: (c) 2021 by the authors. Licensee MDPI, Basel, Switzerland This article is an open access article distributed under the terms and conditions of the Creative Commons Attribution (CC BY) license (https:// creativecommons.org/licenses/by/ $4.0 /)$.

\begin{abstract}
Amino-4-methylcoumarin (AMC) is a low molecular weight fluorescent probe that can be attached to a peptide to enable the detection of specific proteases, such as chymotrypsin, expressed in certain diseases. Because this detection depends on the specificity of the protease toward the peptidyl AMC, the development of specific substrates is required. To investigate the specificity of chymotrypsin, peptidyl AMC compounds incorporating four different amino acid residues were prepared by liquid-phase synthesis. Two unnatural amino acids, 2-amino-4-ethylhexanoic acid $(\mathrm{AEH})$ and cyclohexylalanine (Cha), were used to investigate the substrate specificity as these amino acids have structures different from natural amino acids. AEH was synthesized using diethyl acetamidemalonate as a starting material. The substrate containing Cha had high hydrophobicity and showed a high reaction velocity with chymotrypsin. Although the AEH substrate with a branched side chain had high hydrophobicity, it showed a low reaction velocity. The substrate containing the aromatic amino acid phenylalanine was less hydrophobic than the Cha and AEH substrates, but chymotrypsin showed the highest specificity for this compound. These results demonstrated that the substrate specificity of chymotrypsin is not only affected by the hydrophobicity and aromaticity, but also by the structural expanse of amino acid residues in the substrate.
\end{abstract}

Keywords: unnatural amino acid; peptide; fluorescent probe; 7-amino-4-methylcoumarin; specificity; chymotrypsin

\section{Introduction}

Proteases are proteolytic enzymes that are found extensively in organisms. Proteases play a role in most physiological systems, including digestion, immune response, and cell proliferation [1-4]. However, some proteases are closely related with disease states and genetic abnormalities, including cancer [5,6]. Over expression of certain proteases is known to cause specific diseases $[7,8]$. In the progression of cancer, the over-expression of cathepsin in tumor cells promotes the degradation of the cells and cell re-organization [9] and expression of matrix metalloproteinases in stromal cells assists in tumor cell growth [10]. Over-expression of hepsin in prostate tumors promotes the metastasis and growth of the tumor cells, followed by weakening of the adhesion of the stroma [11]. Quantitative analysis of the protease causing a disease is essential in understanding the progression of the disease. In one study, protease activity related to a disease was successfully detected using synthesized substrates for which the protease had specific activity [12]. The structure of the active site of proteases differs according to the constituent amino acid residues. Chymotrypsin is a general serine protease that is well known structurally and mechanically. Chymotrypsin is not only important for living organisms but is also involved in many diseases [13]; therefore, investigation of the activity of chymotrypsin may lead to more accurate and simpler diagnoses of diseases.

Analysis of the interaction of proteases with substrates can assist in the development and analysis of the characteristics of protease inhibitors [14]. Such analyses are frequently 
performed with fluorescent probes for analysis of the protease activity $[15,16]$. Fluorescent probes enable investigation of the protease activity, simply and at low-cost [17-19]. 7-Amino-4-methylcoumarine (AMC) is usually used as the fluorescent probe for proteases [20-23]. AMC produces different fluorescence states depending on whether or not it is bound to a peptide. Therefore, the degradation of peptide substrates can be observed, which can provide information on the degradation activity of the protease. In the present study, the fluorescent probe AMC was used because it is relatively easy to connect to a peptide.

The aromatic ring of peptide substrates is recognized by chymotrypsin and then the carboxyl-terminus of the peptide is selectively hydrolyzed because the vicinity of the active site of chymotrypsin is hydrophobic $[24,25]$. Leucine (Leu) and valine residues without an aromatic ring are also often recognized and the substrate hydrolyzed by chymotrypsin [26,27]. Substrates with natural amino acids are also known to be hydrolyzed by chymotrypsin [28]. In the present study, substrate peptides containing unnatural amino acids were synthesized, and amino acid residues for which chymotrypsin was highly specific were explored. Unnatural amino acids enable investigation of the specificity that results from the structure of the side chain of compounds because various structures and properties can be imparted to unnatural amino acids. The unnatural amino acids 2-amino-4-ethylhexanoic acid (AEH) and cyclohexylalanine (Cha) were selected for use in the present study because phenylalanine (Phe) tends to be recognized as a substrate of chymotrypsin. The fact that the activity of chymotrypsin has been observed to be high for Phe and low for Leu in previous studies has generally been attributed to the aromatic ring and high hydrophobicity of Phe. To further examine this phenomenon, we compared the effects of unnatural amino acids, using Cha without aromaticity, and AEH with a side chain including a degree of freedom greater than Cha. Therefore, this investigation should provide information for the development of substrates that chymotrypsin has specificity for, which exceeds that of substrates containing natural amino acids.

\section{Materials and Methods}

\subsection{Design of Substrates}

To compare the effects of the side-chain structures of the amino acid residues, a simple and easy sequence, $\mathrm{H}_{2} \mathrm{~N}$-Ala-Ala-XXX-AMC, was adopted for the design of the peptide substrates. Where XXX is either AEH 1, Cha 2, Phe 3, or Leu 4 (Figure 1). The tripeptides were designed with two alanine (Ala) residues to improve the binding to chymotrypsin without interfering with the effects of the residues under investigation (XXX).

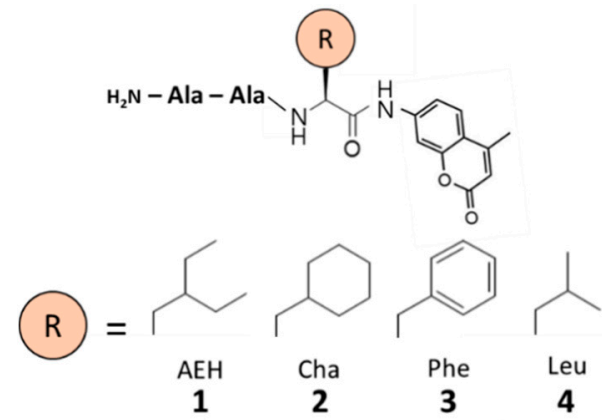

Figure 1. Design of peptide substrates with four different amino acid residues.

\subsection{Synthesis of Boc-AEH-OH}

L-AEH was synthesized as previously described [29]. The progress of the reaction was monitored with thin-layer chromatography, and high-performance liquid chromatography (HPLC) using the following system: pump (L-7100, Hitachi High-Tech Science Corporation, Japan); UV-VIS detector (L-7420, Hitachi High-Tech Science Corporation, Japan); integrator (D-7500, Hitachi High-Tech Science Corporation, Japan); and column (chromolith performance RP-18e 100-4.6 mm, Merck KGaA, Darmstadt, Germany). Diethyl 
acetamidomalonate 5 (50 mmol, 1 eq.) as a starting material was mixed with $20 \%$ sodium ethoxide ethanol solution (50 mmol, 1 eq.) and then the mixture was refluxed for $30 \mathrm{~min}$ in $30 \mathrm{~mL}$ of dehydrated ethanol (Figure 2). Then, 1-bromo-2-ethylbutane (150 mmol, 3 eq.) was added to the mixture, which was refluxed for $3 \mathrm{~h}$. After cooling the mixture in an ice bath, selective hydrolysis was performed by addition of $25 \mathrm{~mL}$ of $1 \mathrm{M} \mathrm{NaOH}$ aqueous solution and stirring for $1 \mathrm{~h}$. After the reaction, the mixture was evaporated under reduced pressure and then washed with diethyl ether, extracted using ethyl acetate at $\mathrm{pH} 3$ (twice), and then washed with brine. The organic layer was dried over $\mathrm{MgSO}_{4}$ and the solvent was evaporated under reduced pressure. The product racemic monocarboxylic acid 6 was obtained as a white solid (28.0 mmol, 56\%). Compound 6 (11.4 mmol) was decarboxylated by refluxing in $100 \mathrm{~mL}$ of toluene for $5 \mathrm{~h}$ and converted to the racemic acyl amino ester. After the reaction, the solvent was removed under reduced pressure and then the resulting oil was dissolved in ethyl acetate. This solution was washed with $4 \% \mathrm{NaHCO}_{3}$ aqueous solution (twice) and brine. The organic layer was dried over $\mathrm{MgSO}_{4}$ and the solvent was removed under reduced pressure and then the product $(11.7 \mathrm{mmol})$ was obtained as an oil. The oil was hydrolyzed by stirring for $2 \mathrm{~h}$ in a mixture of $40 \mathrm{~mL}$ of ethanol and $20 \mathrm{~mL}$ of $2 \mathrm{M} \mathrm{NaOH}$ aqueous solution. The mixture was evaporated under reduced pressure and then extracted using ethyl acetate at pH 3 (three times) and washed with brine. The organic layer was dried over $\mathrm{MgSO}_{4}$ and the solvent was removed under reduced pressure. The product $(8.6 \mathrm{mmol}, 87 \%)$ was obtained as the racemic acyl amino acid 7 . To obtain the L-amino acid, the racemic mixture was separated by deacylation with $0.11 \mathrm{~g}$ of L-amino acylase and $0.011 \mathrm{mg}$ of $\mathrm{CoCl}_{2} 6 \mathrm{H}_{2} \mathrm{O}$ in $20 \mathrm{~mL}$ of water. The reaction was stopped by addition of $1 \mathrm{M} \mathrm{HCl}$ aqueous solution. The mixture was washed using ethyl acetate (three times) and then L-AEH $8(1.3 \mathrm{mmol}, 44 \%)$ was obtained in the aqueous layer. To use L-AEH in the peptide synthesis, $40 \mathrm{~mL}$ of the L-AEH aqueous solution (1.3 mmol, 1.0 eq.) was modified with the Boc group by reaction with a mixture of $\mathrm{Boc}_{2} \mathrm{O}$ (2.6 mmol, 2.0 eq.), triethylamine ( $2.6 \mathrm{mmol}, 2.0 \mathrm{eq}$.), and dioxane at room temperature for $24 \mathrm{~h}$. The mixture was evaporated under reduced pressure and washed with diethyl ether, then extracted using ethyl acetate at $\mathrm{pH} 3$ (three times). The organic layer was dried over $\mathrm{MgSO}_{4}$ and the solvent was evaporated under reduced pressure. To remove impurities, the compound was dissolved in diethyl ether and recrystallized. Finally, Boc-L-AEH-OH 9 (1.0 mmol, 82\%) was obtained as a white solid.

(a)

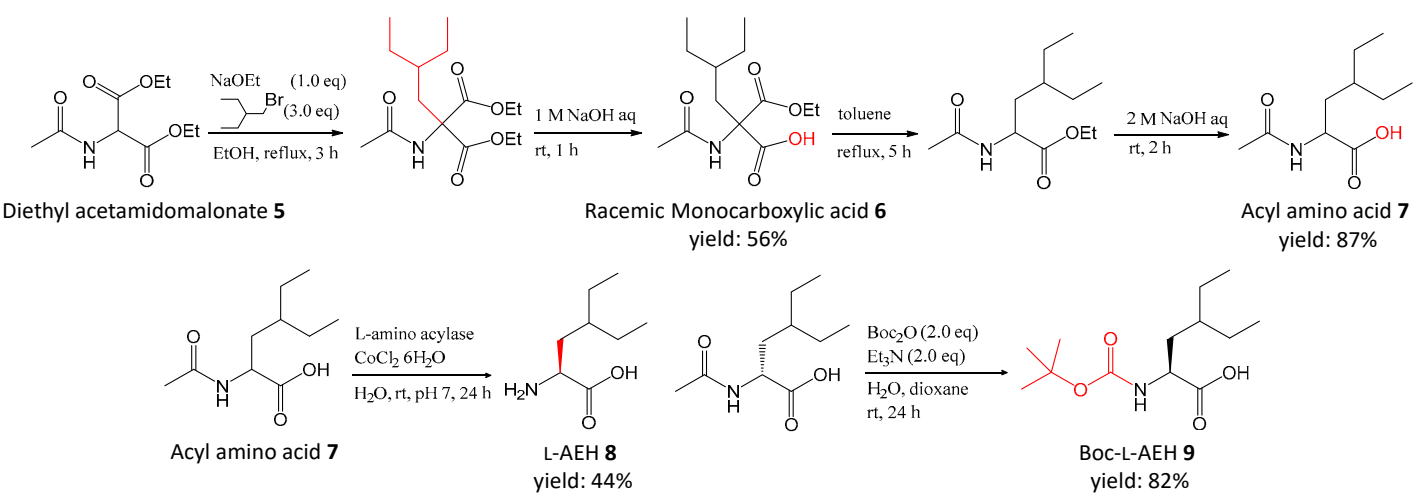

Figure 2. The synthesis of the unnatural amino acid, 2-amino-4-ethylhexanoic acid (AEH). (a) Synthetic scheme for the backbone of racemic AEH. (b) Optical resolution of the acyl-AEH racemic mixture and synthesis of Boc-L-AEH.

\subsection{Synthesis of Peptide-MCA Substrates}

Boc-Leu-OH, Boc-Phe-OH, and Boc-Cha-OH were purchased from Watanabe Chemical Industries, Ltd., Hiroshima, Japan. The four Boc-amino acids, Boc-Leu-OH, BocPhe-OH, Boc-Cha-OH, and Boc-AEH-OH, were each reacted with water soluble carbodiimide hydrochloride (WSC $\mathrm{HCl}, 0.5$ eq.) as a condensing agent in $8 \mathrm{~mL}$ of $N, N$ dimethylformamide (DMF) in an ice bath for $4 \mathrm{~h}$ (Figure 3). Then, these compounds 
were each reacted with AMC (0.5 eq.) for $20 \mathrm{~h}$. In addition, each compound was reacted with WSC $\mathrm{HCl}$ ( 0.25 eq.) overnight. After the reaction, each mixture was evaporated under reduced pressure and then dissolved in ethyl acetate. These solutions were washed using $10 \%$ citric acid aqueous solution (twice), brine, $4 \% \mathrm{NaHCO}_{3}$ aqueous solution (twice), and brine. Each organic layer was dried over $\mathrm{MgSO}_{4}$ and the solvent was evaporated under reduced pressure. The products were obtained as BocXXX-AMC. Peptide synthesis was performed by standard Boc liquid-phase synthesis. The products prepared above were each stirred in $15 \mathrm{~mL}$ of $4 \mathrm{M} \mathrm{HCl}$ /dioxane at room temperature for $30 \mathrm{~min}$ to remove the Boc group. The solvent was evaporated under reduced pressure and then the products $\mathrm{H}_{2} \mathrm{~N}-\mathrm{XXX}-\mathrm{AMC}(\mathrm{XXX}=\mathrm{AEH}: 0.51 \mathrm{mmol}$, Cha: $0.78 \mathrm{mmol}$, Phe: $0.30 \mathrm{mmol}$, and Leu: $0.14 \mathrm{mmol}$ ) were obtained. These compounds were reacted with Boc-Ala-OH (1.2 eq.) using 1-hydroxybenzotriazole ( $\mathrm{HOBt}, 1.2 \mathrm{eq}$.$) , 1-$ [bis(dimethylamino)methylene]-1H-benzotriazolium 3-oxide hexafluorophosphate (HBTU, 1.2 eq.), and $\mathrm{N}, \mathrm{N}$-diisopropylethylamine (DIEA, 3.0 eq.) for $2 \mathrm{~h}$ in $10 \mathrm{~mL}$ of DMF. After the reaction, each mixture was evaporated under reduced pressure and then dissolved in ethyl acetate. The solutions were washed using $10 \%$ citric acid aqueous solution (twice), brine, $4 \% \mathrm{NaHCO}_{3}$ aqueous solution (twice), and brine. Each organic layer was dried over $\mathrm{MgSO}_{4}$ and the solvent was evaporated under reduced pressure. The crude products Boc-Ala-XXX-AMC were obtained. Subsequently, these products (XXX = AEH: $0.36 \mathrm{mmol}$, Cha: $0.72 \mathrm{mmol}$, Phe: $0.32 \mathrm{mmol}$, Leu: $0.21 \mathrm{mmol}$ ) were condensed with Boc-Ala-OH and then extracted as described above to give the products $\mathrm{H}_{2} \mathrm{~N}$-Ala-Ala-XXX-AMC 1-4. These products were purified using HPLC column with a gradient of acetonitrile $/ 0.1 \%$ trifluoroacetic acid from 0 to $100 \%$ for $15 \mathrm{~min}$ at a flow rate of $2.0 \mathrm{~mL} \mathrm{~min}{ }^{-1}$ and identified by mass spectrometry (Figure S1). The values of the mass analysis for each compound were as follows. $X X X=$ AEH $1 \mathrm{~m} / z$ calcd. for $\left[(\mathrm{M}+\mathrm{Na})^{+}\right] \mathrm{C}_{24} \mathrm{H}_{34} \mathrm{~N}_{4} \mathrm{O}_{5}: 481.24269$; found: 481.24294, Cha $2 \mathrm{~m} / z$ calcd. for $\left[(\mathrm{M}+\mathrm{Na})^{+}\right] \mathrm{C}_{25} \mathrm{H}_{34} \mathrm{~N}_{4} \mathrm{O}_{5}$ : 493.24269; found: 493.24139, Phe $3 \mathrm{~m} / z$ calcd. for $\left[(\mathrm{M}+\mathrm{Na})^{+}\right] \mathrm{C}_{25} \mathrm{H}_{28} \mathrm{~N}_{4} \mathrm{O}_{5}: 487.19574$; found: 487.19662, Leu $4 \mathrm{~m} / z$ calcd. for [(M+Na) $\left.{ }^{+}\right] \mathrm{C}_{22} \mathrm{H}_{30} \mathrm{~N}_{4} \mathrm{O}_{5}$ : 453.21139; found: 453.21194 .

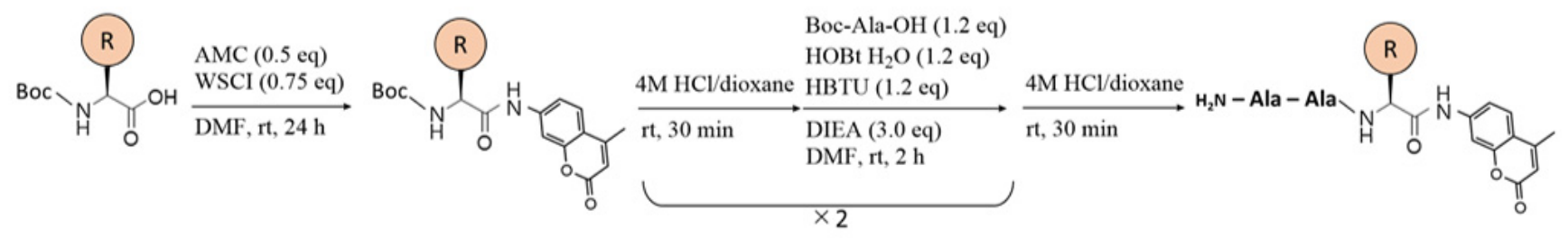

Figure 3. Liquid phase synthesis of the peptide substrates.

\subsection{Chymotrypsin Activity Assay}

Detection of the degradation of each synthesized substrate was performed with a fluorescent plate reader (Wallac ARVO SX 1420 multilabel counter, PerkinElmer Japan Co., Ltd., Kanagawa, Japan). Substrate solutions were prepared at a concentration of $1 \mathrm{mM}$ in dimethyl sulfoxide. A $0.1 \mathrm{M}$ Tris- $\mathrm{HCl}$ buffer was prepared at $\mathrm{pH} 7.8$ and $25^{\circ} \mathrm{C}$. A chymotrypsin (EC 3.4.21.1, bovine pancreas, Sigma-Aldrich Japan, Tokyo, Japan) solution was prepared at a final concentration of $1 \mu \mathrm{M}$ in the buffer. Each substrate solution was prepared at various concentrations to final concentrations of $4,8,16,32,48,64,96$, and $128 \mu \mathrm{M}$ in the buffer, and $190 \mu \mathrm{L}$ of the prepared substrate solutions were put into the wells of a 96-well plate. The measurements were immediately started by addition of $10 \mu \mathrm{L}$ of the chymotrypsin solution. The measurements were performed with linear stirring for $1 \mathrm{~s}$ between a delay of $10 \mathrm{~s}$ at an excitation wavelength of $370 \mathrm{~nm}$ and a detection wavelength of $460 \mathrm{~nm}$. The obtained data was used to calculate the maximum reaction velocity $\left(V_{\max }\right)$, Michaelis constant $\left(K_{m}\right)$, turnover number $\left(k_{\text {cat }}\right)$, and specificity constant $\left(k_{\text {cat }} / K_{m}\right)$ based on the Michaelis-Menten equation. 


\section{Results and Discussion}

\subsection{Hydrophobicity of the Peptide Substrates}

The hydrophobicity of the substrate affects the interaction with chymotrypsin because of the high hydrophobicity around the active site of chymotrypsin. To compare the interaction of the four synthesized peptide substrates with chymotrypsin, the hydrophobicity of each substrate was investigated (Figure 4). The relative hydrophobicity of the peptide substrates could be determined based on the retention times in the HPLC used for purification. The retention times increased depending on the hydrophobicity of peptide. Substrate 2 with the unnatural amino acid Cha had a retention time of $5.58 \mathrm{~min}$ and possessed the highest hydrophobicity. The peptide substrate with the synthesized AEH residue $\mathbf{1}$ had a retention time of $5.34 \mathrm{~min}$ and possessed the next highest hydrophobicity. The Phe substrate 3 and Leu substrate 4 had retention times of 4.75 and $4.62 \mathrm{~min}$, respectively, indicating lower hydrophobicity than the Cha 2 and AEH 1 substrates. The presence of the $\pi$ electrons in the Phe residue with an aromatic ring was thought to cause the lower hydrophobicity of substrate 3 . In contrast, it was thought that the Cha $\mathbf{2}$ and AEH $\mathbf{1}$ substrates exhibited relatively higher hydrophobicity because of their aliphatic ring and branched chain structures, respectively.

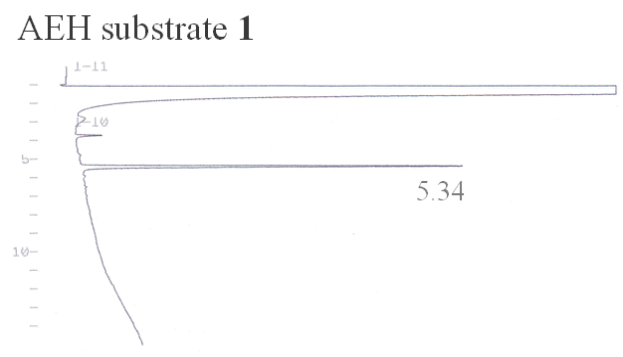

Cha substrate 2

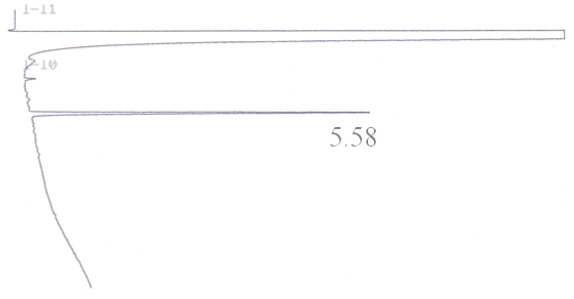

Phe substrate 3

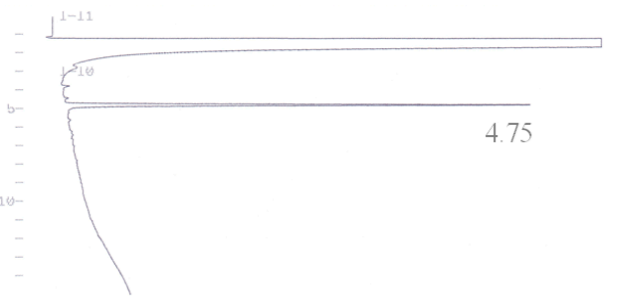

Leu substrate 4

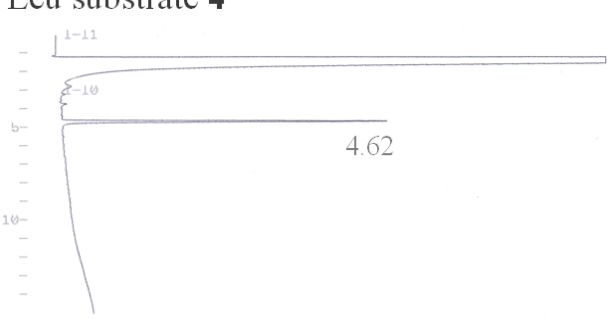

Figure 4. HPLC data of the four synthesized substrates. The values indicate the retention times.

\subsection{Chymotrypsin Activity of the Peptide Substrates}

The specificity of chymotrypsin for the four peptide substrates was compared at various substrate concentrations. The activity of chymotrypsin toward the substrates was measured based on the fluorescence intensity of AMC resulting from the degradation of the substrate. The fluorescence intensity produced by the degradation increased over time for all the substrates. These results indicated that all the synthesized substrates can be recognized and degraded by chymotrypsin. The kinetics of all the synthesized substrates could be fitted to a Michaelis-Menten graph (Figure 5). To compare the preference of chymotrypsin for the synthesized substrates, the $V_{\text {max }}, K_{m}, k_{\text {cat }}$, and $k_{\text {cat }} / K_{m}$ values, which characterize the interaction between an enzyme and a substrate, were calculated based on the Michaelis-Menten equation (Table 1). The Cha substrate $\mathbf{2}$ showed the largest $V_{\max }$ and $k_{\text {cat }}$ values, followed by the Phe substrate 3 . These values broadly agreed with those previously reported for chymotrypsin under similar conditions [30]. In addition, the $V_{\max }$ and $k_{\text {cat }}$ values were dependent on the hydrophobicity of the substrates, except for the Phe substrate 3 . Because of the differences in these peptide substrates, the hydrophobicity and presence or absence of aromaticity may have affected the reaction velocity with chymotrypsin. The AEH substrate $\mathbf{1}$ showed approximately 6 -fold lower $V_{\max }$ and $k_{\text {cat }}$ values than the Phe substrate 3, despite showing a high hydrophobicity in the four peptide 
substrates. This result may be caused by the side chain of the AEH residue that has a high structural degree of freedom. Therefore, the reaction velocity of chymotrypsin for a substrate was affected by the hydrophobicity, aromaticity, and the side chain structure of the recognized amino acid residues.

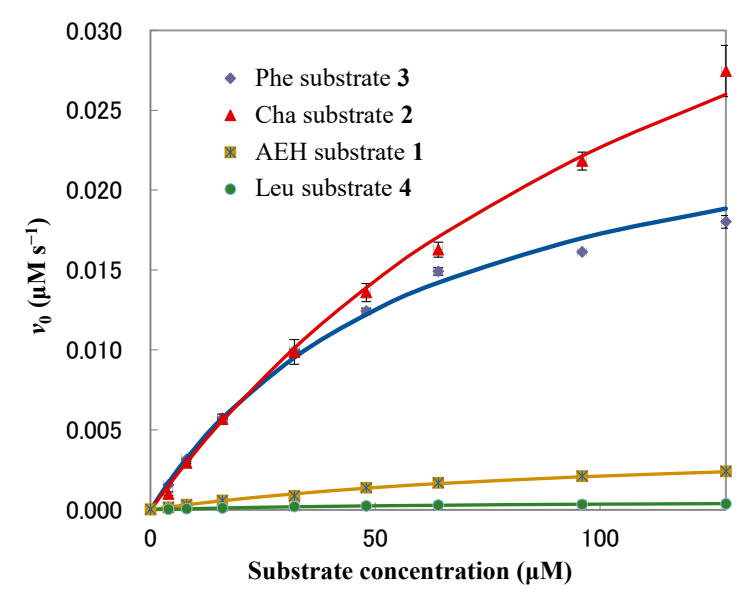

Figure 5. Michaelis-Menten graph of the four synthetic substrates with chymotrypsin.

Table 1. The hydrophobicity and kinetics values of the four peptide substrates.

\begin{tabular}{|c|c|c|c|c|c|}
\hline Sample & $\begin{array}{c}\text { HPLC Retention Time } \\
\text { (min) }\end{array}$ & $\begin{array}{c}V_{\max } \\
\left(\mathrm{nM} \mathrm{s}^{-1}\right)\end{array}$ & $\begin{array}{c}K_{m} \\
(\mu \mathrm{M})\end{array}$ & $\begin{array}{l}k_{\text {cat }} \\
\left(s^{-1}\right)\end{array}$ & $\begin{array}{c}k_{\mathrm{cat}} / K_{m} \\
\left(\mathrm{M}^{-1} \mathrm{~s}^{-1}\right)\end{array}$ \\
\hline Leu substrate 4 & 4.62 & $0.60 \pm 0.01$ & $72.83 \pm 1.22$ & $(0.60 \pm 0.01) \times 10^{-3}$ & $8.21 \pm 0.03$ \\
\hline AEH substrate $\mathbf{1}$ & 5.34 & $4.36 \pm 0.09$ & $107.79 \pm 3.12$ & $(4.36 \pm 0.09) \times 10^{-3}$ & $40.67 \pm 0.43$ \\
\hline Cha substrate 2 & 5.58 & $54.54 \pm 1.62$ & $140.48 \pm 5.65$ & $(5.45 \pm 0.16) \times 10^{-2}$ & $388.32 \pm 4.54$ \\
\hline Phe substrate 3 & 4.75 & $27.96 \pm 0.71$ & $61.97 \pm 2.40$ & $(2.80 \pm 0.07) \times 10^{-2}$ & $452.35 \pm 6.62$ \\
\hline Suc-F-pNA ${ }^{a}$ & & & 720 & 0.011 & 15 \\
\hline A-A-F-AMC ${ }^{a}$ & & & 500 & 0.83 & 2000 \\
\hline
\end{tabular}

a Data from 30.

Next, the $K_{m}$ values, which indicate the affinity between the peptide substrate and chymotrypsin, were compared. Smaller $K_{m}$ values indicate higher affinity. The Phe substrate 3 showed the lowest $K_{m}$ value, indicating the highest affinity for chymotrypsin. The Cha 2 and AEH 1 substrates with higher hydrophobicity showed approximately two-fold larger $K_{m}$ values than that of the Phe substrate 3 , indicating lower affinity. The low affinity of the Cha 3 and AEH 1 substrates may be related to the large structural degree of freedom that the side chains of the Cha and AEH residues possess. In contrast, the structure of the Leu and Phe residues allows these substrates to easily enter the hydrophobic pocket near the active site of chymotrypsin. In addition, chymotrypsin tends to recognize aromatic amino acid residues and is well known to recognize the aromatic ring of Phe residues. Thus, chymotrypsin may preferentially recognize amino acid residues that possess aromaticity or have a smaller structural degree of freedom.

Finally, the $k_{\text {cat }} / K_{m}$ values of each substrate were compared. The $k_{\text {cat }} / K_{m}$ value represents the specificity of the enzyme for the substrate. The Phe substrate 3 showed the highest $k_{\text {cat }} / K_{m}$ value, indicating high specificity of chymotrypsin for substrate 3 . The $k_{\text {cat }} / K_{m}$ values of the Cha and AEH substrates with higher hydrophobicity than the Phe substrate 3 were lower than those of the Phe substrate 3 . These results suggested that the specificity of chymotrypsin for a particular substrate may be because of the presence of an aromatic amino acid residue rather than a hydrophobic amino acid residue. The $k_{\text {cat }} / K_{m}$ value of the Cha substrate 2 with greater hydrophobicity than the AEH substrate 1 was 9-fold larger than that of the AEH substrate 1 . The least hydrophobic Leu substrate 4 showed the lowest $k_{\text {cat }} / K_{m}$ value. The $k_{\text {cat }} / K_{m}$ values for each substrate increased with 
increasing hydrophobicity, except for the Phe substrate 3 . These results indicated that the specificity of chymotrypsin for a substrate increased with increasing hydrophobicity of the substrate. Although of the four peptide substrates, the Phe substrate 3 has relatively low hydrophobicity, the high specificity of chymotrypsin for substrate 3 may be because of the aromaticity and the planar structure of the Phe residue, which has less steric hindrance than the AEH 1 and Cha 3 substrates. Therefore, high substrate specificity for chymotrypsin requires aromaticity, high hydrophobicity, and low steric hindrance at the recognition site for the substrate. These properties are important for controlling the specificity of chymotrypsin for a substrate, and unnatural amino acid residues are useful to investigate this substrate specificity.

\section{Conclusions}

AEH was successfully synthesized using diethyl acetamidomalonate as a starting material and enzymatic optical resolution. The synthesized AEH was incorporated into a tripeptide as a novel peptide substrate. Novel peptide substrates with the unnatural amino acid residues, $\mathrm{AEH}$ and $\mathrm{Cha}$, showed high hydrophobicity that contributed to increased chymotrypsin specificity. In particular, the Cha substrate 2 was the most hydrophobic and showed a high reaction velocity with chymotrypsin. On the other hand, chymotrypsin was less specific for the AEH substrate 1 because of the structural degree of freedom caused by the branched side-chain structure of the AEH residue. This degree of freedom increases the space in which this amino acid side chain can exist dynamically, which may have affected the enzyme-substrate interaction. From a comparison of the peptide substrates containing natural amino acids, the specificity of chymotrypsin was determined to be greatly affected by the substrate's hydrophobicity, aromaticity, and the conformation of the amino acid residue at the recognition site. The unnatural amino acids in this study were used to investigate the specificity of chymotrypsin for substrates with side-chain structures with a branched chain or an aliphatic ring. Unnatural amino acids with structures different from natural amino acids can be used in further investigations into the specificity of protease enzymes, including chymotrypsin.

Supplementary Materials: The following are available online at https:/ /www.mdpi.com/2227-9 717/9/2/242/s1, Figure S1: MS data of the four synthesized substrates $\mathrm{H}_{2} \mathrm{~N}$-Ala-Ala-XXX-AMC, where XXX is either AEH 1, Cha 2, Phe 3, or Leu 4.

Author Contributions: Conceptualization, Y.Y. and T.K.; substrate synthesis, T.Y.; data analysis, Y.Y.; writing-original draft preparation, Y.Y.; writing-review and editing, T.K.; supervision, T.K. All authors have read and agreed to the published version of the manuscript.

Funding: This research received no external funding.

Institutional Review Board Statement: Not applicable.

Informed Consent Statement: Not applicable.

Data Availability Statement: The data presented in this study are available in article and supplementary material.

Conflicts of Interest: The authors declare no conflict of interest.

\section{References}

1. Turk, V.; Stoka, V.; Vasiljeva, O.; Renko, M.; Sun, T.; Turk, B.; Turk, D. Cysteine Cathepsins: From Structure, Function and Regulation to New Frontiers. Biochim. Biophys. Acta Proteins Proteom. 2012, 1824, 68-88. [CrossRef] [PubMed]

2. Figueiredo, J.-L.; Aikawa, M.; Zheng, C.; Aaron, J.; Lax, L.; Libby, P.; Filho, J.L.d.L.; Gruener, S.; Fingerle, J.; Haap, W.; et al. Selective Cathepsin S Inhibition Attenuates Atherosclerosis in Apolipoprotein E-Deficient Mice with Chronic Renal Disease. Am. J. Pathol. 2015, 185, 1156-1166. [CrossRef] [PubMed]

3. Kim, J.; Yu, W.; Kovalski, K.; Ossowski, L. Requirement for Specific Proteases in Cancer Cell Intravasation as Revealed by a Novel Semiquantitative PCR-Based Assay. Cell 1998, 94, 353-362. [CrossRef]

4. Pham, C.T.N.; Ley, T.J. Dipeptidyl Peptidase I Is Required for the Processing and Activation of Granzymes A and B In Vivo. Proc. Natl. Acad. Sci. USA 1999, 96, 8627-8632. [CrossRef] 
5. Hart, T.C.; Harta, P.S.; Bowden, D.W.; Michalec, M.D.; Callison, S.A.; Walker, S.J.; Zhang, Y.; Firatli, E. Mutations of the Cathepsin C Gene Are Responsible for Papillon-Lefèvre Syndrome. J. Med. Genet. 1999, 36, 881-887.

6. Hart, T.C.; Hart, P.S.; Michalec, M.D.; Zhang, Y.; Firatli, E.; Dyke, T.E.V.; Stabholz, A.; Zlorogorski, A.; Shapira, L.; Soskolne, W.A. Haim-Munk Syndrome and Papillon-Lefèvre Syndrome Are Allelic Mutations in Cathepsin C. J. Med. Genet. 2000, $37,88-94$. [CrossRef]

7. Gocheva, V.; Joyce, J.A. Cysteine Cathepsins and the Cutting Edge of Cancer Invasion. Cell Cycle 2007, 6, 60-64. [CrossRef]

8. Adkison, A.M.; Raptis, S.Z.; Kelley, D.G.; Pham, C.T.N. Dipeptidyl Peptidase I Activates Neutrophil-Derived Serine Proteases and Regulates the Development of Acute Experimental Arthritis. J. Clin. Investig. 2002, 109, 363-371. [CrossRef]

9. Yang, Y.; Hong, H.; Zhang, Y.; Cai, W. Molecular Imaging of Proteases in Cancer. Cancer Growth Metastasis 2009, 17, 13-27. [CrossRef]

10. McKerrow, J.H.; Bhargava, V.; Hansell, E.; Huling, S.; Kuwahara, T.; Matley, M.; Coussens, L.; Warren, R. A Functional Proteomics Screen of Proteases in Colorectal Carcinoma. Mol. Med. 2000, 6, 450-460. [CrossRef]

11. Klezovitch, O.; Chevillet, J.; Mirosevich, J.; Roberts, R.L.; Matusik, R.J.; Vasioukhin, V. Hepsin Promotes Prostate Cancer Progression and Metastasis. Cancer Cell 2004, 6, 185-195. [CrossRef] [PubMed]

12. Łegowska, M.; Hamon, Y.; Wojtysiak, A.; Grzywa, R.; Sieńczyk, M.; Burster, T.; Korkmaz, B.; Lesner, A. Development of the First Internally-Quenched Fluorescent Substrates of Human Cathepsin C: The Application in the Enzyme Detection in Biological Samples. Arch. Biochem. Biophys. 2016, 612, 91-102. [CrossRef] [PubMed]

13. Yamashita, S.; Sakabe, M.; Ishizawa, T.; Hasegawa, K.; Urano, Y.; Kokudo, N. Visualization of the Leakage of Pancreatic Juice Using a Chymotrypsin-Activated Fluorescent Probe. Br. J. Surg. 2013, 100, 1220-1228. [CrossRef] [PubMed]

14. Poreba, M.; Mihelic, M.; Krai, P.; Rajkovic, J.; Krezel, A.; Pawelczak, M.; Klemba, M.; Turk, D.; Turk, B.; Latajka, R.; et al. Unnatural Amino Acids Increase Activity and Specificity of Synthetic Substrates for Human and Malarial Cathepsin C. Amino Acids 2014, 46, 931-943. [CrossRef] [PubMed]

15. Imamura, T.; Matsushita, K.; Travis, J.; Potempa, J. Inhibition of Trypsin-Like Cysteine Proteinases (Gingipains) from Porphyromonas gingivalis by Tetracycline and Its Analogues. Antimicrob. Agents Chemother. 2001, 45, 2871-2876. [CrossRef]

16. Mittoo, S.; Sundstrom, L.E.; Bradley, M. Synthesis and Evaluation of Fluorescent Probes for the Detection of Calpain Activity. Anal. Biochem. 2003, 319, 234-238. [CrossRef]

17. Steimle, A.; Kalbacher, H.; Maurer, A.; Beifuss, B.; Bender, A.; Schäfer, A.; Müller, R.; Autenrieth, I.B.; Frick, J.-S. A Novel Approach for Reliable Detection of Cathepsin S Activities in Mouse Antigen Presenting Cells. J. Immunol. Methods 2016, 432, 87-94. [CrossRef]

18. Tokmina-Roszyk, M.; Tokmina-Roszyk, D.; Bhowmick, M.; Fields, G.B. Development of a Förster Resonance Energy Transfer Assay for Monitoring Bacterial Collagenase Triple-Helical Peptidase Activity. Anal. Biochem. 2014, 453, 61-69. [CrossRef]

19. Sato, D.; Kato, T. Novel Fluorescent Substrates for Detection of Trypsin Activity and Inhibitor Screening by Self-Quenching. Bioorganic Med. Chem. Lett. 2016, 26, 5736-5740. [CrossRef]

20. Zimmerman, M.; Yurewicz, E.; Patel, G. A New Fluorogenic Substrate for Chymotrypsin. Anal. Biochem. 1976, 70, 258-262. [CrossRef]

21. Tran, T.V.; Ellis, K.A.; Kam, C.-M.; Hudig, D.; Powers, J.C. Dipeptidyl Peptidase I: Importance of Progranzyme Activation Sequences, Other Dipeptide Sequences, and the N-Terminal Amino Group of Synthetic Substrates for Enzyme Activity. Arch. Biochem. Biophys. 2002, 403, 160-170. [CrossRef]

22. Kraft, M.; Radke, D.; Wieland, G.D.; Zipfel, P.F.; Horn, U. A Fluorogenic Substrate as Quantitative In Vivo Reporter to Determine Protein Expression and Folding of Tobacco Etch Virus Protease in Escherichia coli. Protein Expr. Purif. 2007, 52, 478-484. [CrossRef] [PubMed]

23. Schulze, A.; Wermann, M.; Demuth, H.-U.; Yoshimoto, T.; Ramsbeck, D.; Schlenzig, D.; Schilling, S. Continuous Assays for Meprin Alpha and Beta Using Prolyl Tripeptidyl Aminopeptidase (PtP) from Porphyromonas gingivalis. Anal. Biochem. 2018, 559, 11-16. [CrossRef] [PubMed]

24. Bergmann, B.M.; Fruton, J.S. On Proteolytic Enzymes: XIII. Synthetic Substrates for Chymotrypsin. J. Biol. Chem. 1937, 118, 405-415. [CrossRef]

25. Fruton, J.S.; Bergmann, M. The Multiple Specificity of Chymotrypsin. J. Biol. Chem. 1942, 145, 253-265. [CrossRef]

26. Hein, G.E.; Jones, J.B.; Niemann, C. The Kinetics of the $\alpha$-Chymotrypsin-Catalyzed Hydrolysis of Acetyl-L-leucine Methyl Ester. Biochim. Biophys. Acta 1962, 65, 353-355. [CrossRef]

27. Waite, H.R.; Niemann, C. The $\alpha$-Chymotrypsin-Catalyzed Hydrolysis of a Series of Acylated-L-valine Esters. Biochemistry 1962, 1 , 250-253. [CrossRef]

28. Spreti, N.; Mancini, M.V.; Germani, R.; Profio, P.D.; Savelli, G. Substrate Effect on $\alpha$-Chymotrypsin Activity in Aqueous Solutions of "Big-Head" Ammonium Salts. J. Mol. Catal. 2008, 50, 1-6. [CrossRef]

29. Watanabe, L.A.; Jose, B.; Kato, T.; Nishino, N.; Yoshida, M. Synthesis of 1- $\alpha$-amino- $\omega$-bromoalkanoic Acid for Side Chain Modification. Tetrahedron Lett. 2004, 45, 491-494. [CrossRef]

30. DelMar, E.G.; Largman, C.; Brodrick, J.W.; Geokas, M.C. A Sensitive New Substrate for Chymotrypsin. Anal. Biochem. 1979, 99, 316-320. [CrossRef] 